\title{
Adrenal cortical tumours: epidemiological and familial aspects
}

\author{
A L HARTLEY, J M BIRCH, H B MARSDEN, H REID, M HARRIS, AND V BLAIR \\ Departments of Epidemiology and Social Oncology and Pathology Christie Hospital and Holt Radium \\ Institute, and the Department of Pathology, University of Manchester Medical School, Manchester
}

SUMMARY Epidemiological data on the 14 cases of adrenal cortical tumour registered with the Manchester Children's Tumour Registry from 1954 and 1985 are presented. The incidence of adrenal cortical carcinomas was $0.3 \%$, mainly in girls, most of whom presented with virilisation. The incidence of neoplastic disease among close relatives was ascertained, but, except in siblings, this was not significantly higher than would be expected. Evidence from extended pedigrees, however, indicates that at least four of the children could be members of families with the SBLA (sarcoma, breast and brain tumour, ieukaemia, laryngeal and lung cancer, and adrenal cortical carcinoma) cancer family syndrome, and that other relatives may be at risk of developing such neoplasms.

Adrenal cortical tumours are rare in children, the incidence of adrenal cortical carcinoma being estimated as $0 \cdot 2 \%$ of all childhood malignancies. ${ }^{1}$ In spite of this there have been several reports of associations between adrenal cortical tumours and certain congenital malformations and growth disorders, such as hemihypertrophy, BeckwithWiedemann syndrome, and malformations of the urinary tract. ${ }^{23}$ Adrenal carcinoma has also been reported in patients with Gardner's syndrome. ${ }^{4}$ Adrenal cortical carcinoma may also predispose to second malignancies, and survivors may later develop brain tumours, ${ }^{2}$ melanoma, ${ }^{5}$ and certain tumours induced by radiation-for example, osteogenic sarcoma ${ }^{2}$ and renal cell carcinoma. ${ }^{6}$

Adrenal cortical tumours are known to be part of a familial syndrome including sarcomas, brain tumours, breast cancer and leukaemias. In one family described by Kenny et al: ${ }^{7}$ the father and sister of an affected child developed 'bone tumours' at the ages of 29 and 9, respectively. In another family the mother and maternal aunt both had breast cancer diagnosed in their $30 \mathrm{~s}$, while a maternal uncle had a brain tumour at the age of 39 , and a maternal cousin also developed an adrenal tumour in infancy. 7 The occurrence of bilateral breast cancer in the mother of two siblings with adrenal cortical carcinoma was reported by Shimke. ${ }^{8}$

In an extensive family described by Lynch et al there were two adrenal cortical tumours, one in a man aged 23 , and one in a girl of $3 .{ }^{9} \mathrm{Li}$ and Fraumeni previously reported the association between soft tissue sarcoma in childhood and the early onset of breast cancer in the mothers of these children. ${ }^{10}$ Both of the first two such families reported in England by Pearson et al included a child with adrenal cortical carcinoma. ${ }^{11}$

In the report by Kenny et al, of seven cases of virilising adrenal cortical tumour, four of the seven cases had a notable family history of malignancy. ${ }^{7}$ Most families with the sarcoma, breast and brain tumour, leukaemia, laryngeal and lung cancer and adrenal cortical carcinoma (SBLA cancer family) syndrome reported so far, however, have been selectively documented, usually because of cases of cancer in other family members. To what extent the occurrence of an adrenal cortical tumour in an individual indicates that he or she is part of a "cancer family' is not known. The aim of this paper is to present epidemiological data about the incidence of adrenal cortical tumours in a population based series, and to shed light on the association between other neoplasms and adrenal cortical tumours: surveillance programmes for early detection of cancers in relatives may thus be more effectively deployed.

\section{Methods}

All cases of adrenal cortical tumour in the Manchester Children's Tumour Registry diagnosed between 
1 January 1954 and 31 December 1985 were included in the study. The Manchester Children's Tumour Registry was described in detail by Birch $e t$ $a l,{ }^{12}$ and it was estimated to be $95-98 \%$ complete. ${ }^{13}$ The histology slides of all cases were reviewed to confirm the diagnosis.

The following information was abstracted from the records of each child included in the study: sex, age at diagnosis, side of the tumour, presenting symptoms, congenital abnormalities and other medical history, and, where available, family history of cancer.

The current general practitioners of both parents of each child were then identified with the help of family practitioner committees, the National Health Service central register and other local sources. These methods were described by Birch et al. ${ }^{14}$ The general practitioners were then given details of the study and asked for permission to approach the family for interview. This was usually done by letter, but in the case of children who were still attending for follow up the hospital consultant's permission was sought and the parents contacted at their next visit to the clinic.

Parents were usually interviewed at home. They were asked about the child's medical history, including congenital abnormalities, serious acute and chronic illnesses, and operations. Similar details were obtained for all first degree relatives - that is parents and siblings. Reports of serious malformations and neoplasms were recorded for all second degree relatives, and for third degree and more distant relatives when possible. Dates of birth or ages of all first and second degree relatives were obtained so that relative risk ratios for the development of malignancies could be calculated. In addition, parents were asked about occupational exposures to chemicals and radiation before the birth of the index child. To obtain consistent information from parents, check lists of diseases and substances were used.

Reports of all serious medical conditions in the child were confirmed from hospital records or by correspondence with general practitioners. We tried to confirm reports of all neoplastic conditions in relatives by reference to hospital notes, the appropriate regional cancer registry, questionnaires to general practitioners, or from copies of death certificates. Where possible the histological slides were reviewed. If parents or siblings had died before the interview the cause of death was confirmed from medical records.

The cumulative risks of developing cancer at a particular age were estimated for all first and second degree relatives using data from the North West region. ${ }^{15}$ These were used to calculate the expected numbers of cancers among these relatives, taking into account their age at the time of interview, or at death, as appropriate. The method described by Rothman and Boice for exact testing and estimation of a Poisson variate was used to test whether the observed numbers of cancers were greater than expected. ${ }^{16}$

\section{Results}

There were 12 boys and two girls with adrenal cortical tumours between 1954-85 who were registered with the Manchester Children's Tumour Registry. Four of the tumours were classified as adenomas, the rest being carcinomas. For the 30 years for which population data are available, this represents an incidence of adrenal cortical tumours of about 1 in 500000 in boys, 1 in 87000 in girls, or 1 in 150000 overall. Adrenal cortical carcinomas in this series comprised $0.3 \%$ of all childhood malignancies registered with the Manchester Children's Tumour Registry.

Age at diagnosis ranged from 8 months to 12 years 7 months (median 3 years 9 months). Most of the children presented with precocious sexual development with virilisation. Six cases also had Cushing's syndrome, but abdominal pain or mass was the only presenting symptom in two of the girls. The adenomas ranged from $3-6 \mathrm{~cm}$ in diameter, and the carcinomas from $8-25 \mathrm{~cm}$.

All patients were treated by surgery, and some had radiotherapy either postoperatively or for recurrent disease. Five children were treated by chemotherapy for recurrences. Table 1 gives details of all the cases, together with presenting symptoms, treatment, and outcome. Cases 1, 2, 7, and 13 have previously been described by Stewart et al, ${ }^{17}$ and case 4 by Pearson et al. ${ }^{11}$

Thirteen families were interviewed, and the remaining set of parents completed a postal questionnaire. Both parents were seen in only three cases; two mothers and two fathers were already dead and four sets of parents were divorced. In cases where the mothers had died the interview was carried out with the father in one case, and with the maternal grandparents in the other.

Medical History of the children and their relatives. All the children were born at full term except case 4 ( 37 weeks) and case 5 (33 weeks because of maternal diabetes and hypertension). Delivery was normal or by forceps except for case 5, who was born by caesarean section. Birth weights were available for 13 cases and ranged from $1600 \mathrm{~g}$ (case 5) to $4800 \mathrm{~g}$ (mean $3500 \mathrm{~g}$, median $3800 \mathrm{~g}$ ). The ages of the mothers at the birth of the child ranged from 23 to 
39 years (mean 28 years 10 months, median 31 years 6 months). Six mothers and eight fathers were 30 years or over at the birth of the child.

Table 2 shows the congenital abnormalities in the children, their parents, and siblings, and Table 3 lists other conditions. Other conditions in second and higher degree relatives included hypercholesterolaemia (maternal aunt of case 7); pernicious anaemia (paternal aunt of case 3); possible velo-cardio-facial syndrome (maternal aunt of case 8); sebaceous cysts (maternal grandmother of case 6) and a major congenital heart abnormality (maternal first cousin of case 14).

Exposure to potentially toxic substances. Information on parental exposure to such substances was difficult to obtain, but four mothers and seven fathers had been exposed to various dusts and chemicals before or during the index pregnancy.
These included cotton and wool dusts, solvents, tar, chemicals, insulation materials, dyes and possibly fertilisers. One father had been a chemical process worker before the child's birth, and three parentsincluding both the mother and father of case 13-had worked in the rubber industry.

Cancers in first and second degree relatives. Table 4 shows the observed and expected numbers of cancers in first degree relatives, and in those second degree relatives for whom information was obtained. The mother of case 4 developed infiltrating duct carcinoma of the breast at the age of 27 , and the father of case 11 died of a brain tumour, probably a glioma, at the age of 35 . Information on 20 brothers and 16 sisters was available, and only one had developed a malignancy; the brother of case 4 developed a dense, poorly differentiated rhabdomyosarcoma of the middle ear at the age of 19

Table 1 Adrenal cortical tumours in the Manchester Children's Tumour Registry 1954-1985

\begin{tabular}{|c|c|c|c|c|c|c|}
\hline $\begin{array}{l}\text { Case } \\
\text { No }\end{array}$ & Sex & Diagnosis & $\begin{array}{l}\text { Age at } \\
\text { diagnosis } \\
\text { (months) }\end{array}$ & Symptoms & $\begin{array}{l}\text { Initial } \\
\text { treatment }\end{array}$ & $\begin{array}{l}\text { Outcome and } \\
\text { survival }\end{array}$ \\
\hline 2 & Female & Right carcinoma & 10 & $\begin{array}{l}\text { Virilisation, precocious development. } \\
\text { abdominal mass }\end{array}$ & Surgery and radiotherapy & Alive (19 years) \\
\hline 3 & Female & Right carcinoma & 16 & Virilisation & Surgery and radiotherapy & Alive ( 11 years) \\
\hline 5 & Female & Right carcinoma & 34 & $\begin{array}{l}\text { Virilisation, acne, } \\
\text { abdominal mass }\end{array}$ & Surgery and radiotherapy & Alive ( 10 months) \\
\hline 6 & Female & Left carcinoma & 36 & $\begin{array}{l}\text { Virilisation, Cushing's } \\
\text { syndrome, acne }\end{array}$ & Surgery and radiotherapy & Dead (27 months) \\
\hline 7 & Female & Left adenoma & 38 & $\begin{array}{l}\text { Virilisation, Cushing`s syndrome. } \\
\text { precocious development }\end{array}$ & Surgery & Alive (24 years) \\
\hline 8 & Female & Right carcinoma & 52 & Abdominal pain, mass & Surgery and radiotherapy & Dead (20 months) \\
\hline 9 & Female & Right adenoma & 66 & $\begin{array}{l}\text { Virilisation, acne, precocious } \\
\text { development }\end{array}$ & Surgery & Alive ( 7 years) \\
\hline 12 & Female & Left carcinoma & 126 & Cushing's syndrome & Surgery & Dead (3 weeks) \\
\hline 13 & Male & Left carcinoma & 140 & Cushing's syndrome, abdominal pain & Surgery & Dead ( 8 months) \\
\hline 14 & Female & Left carcinoma & 151 & Virilisation; Cushing syndrome & Surgery and radiotherapy & Dead $(10$ months $)$ \\
\hline
\end{tabular}

Table 2 Congenital abnormalities in case children, parents, and siblings

\begin{tabular}{|c|c|c|c|}
\hline Case No & Child & Parents & Siblings \\
\hline 2 & Haemangioma left shoulder & & - \\
\hline 3 & Small white patch on leg & & - \\
\hline 5 & $\begin{array}{l}\text { Head circumference just below } \\
\text { 90th centile }\end{array}$ & & - \\
\hline 6 & $\begin{array}{l}\text { Two small brown patches on abdomen } \\
\text { and foot }\end{array}$ & & - \\
\hline 7 & & Brown mark on chest (mother) & Brown mark on leg (sister) \\
\hline 8 & & & $\begin{array}{l}\text { Spastic and mentally retarded; squint and } \\
\text { ocular hypertelorism, epicanthic folds } \\
\text { (brother) }\end{array}$ \\
\hline 10 & Slight right hemihypertrophy & $\begin{array}{l}\text { Bifid left renal pelvis and duplication } \\
\text { of ureter in its upper quarter (mother) }\end{array}$ & \\
\hline 13 & & & Bilateral talipes equino varus (brother) \\
\hline
\end{tabular}


Table 3 Other non-neoplastic conditions in case children, parents, and siblings

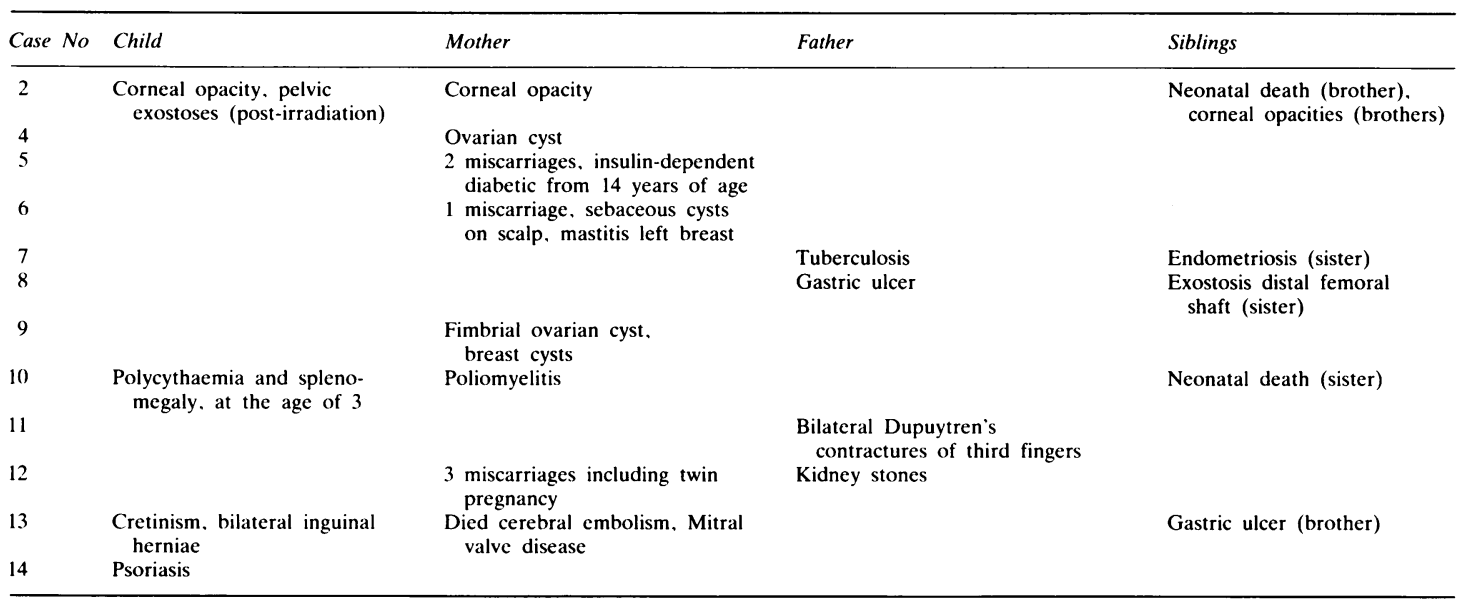

Table 4 Cancer risk in first and second degree relatives of children with adrenal cortical tumours

\begin{tabular}{|c|c|c|c|c|c|}
\hline & $\begin{array}{l}\text { Total } \\
\text { No }\end{array}$ & $\begin{array}{l}\text { Observed } \\
\text { No }\end{array}$ & $\begin{array}{l}\text { Expected } \\
\text { No }\end{array}$ & Relative risk & $p$ value \\
\hline Mothers & 14 & 1 & 0.58 & 1.7 & 0.28 \\
\hline Fathers & 14 & 1 & 0.78 & $1 \cdot 3$ & 0.36 \\
\hline Brothers & 20 & 1 & 0.07 & $14 \cdot 3$ & 0.035 \\
\hline Sisters & 16 & 0 & 0.07 & - & 0.53 \\
\hline Grandfathers & 24 & 4 & $3 \cdot 8$ & 0.9 & 0.43 \\
\hline Grandmothers & 26 & 4 & $4 \cdot 4$ & 0.9 & 0.54 \\
\hline Aunts & 37 & 1 & $2 \cdot 3$ & 0.4 & 0.78 \\
\hline Uncles & 40 & 2 & $2 \cdot 6$ & $0 \cdot 8$ & 0.61 \\
\hline
\end{tabular}

months. The maximum age of the siblings, however, was only 38 years.

Four grandfathers had confirmed cancer. These included carcinoma of stomach at the age of 76 (maternal grandfather of case 11); carcinoma of prostàte at the age of 70 (paternal grandfather of case 11); carcinoma of lung at the age of 65 (paternal grandfather of case 14), and a brain tumour at the age of 35 (paternal grandfather of case 5). Three grandmothers also had cancer: the maternal grandmother of case 9 had a double primary tumour-a carcinoma of cervix at the age of 54 and a carcinoma of breast at the age of 65 . The maternal grandmother of case 3 also had breast cancer at the age of 47 , and the maternal grandmother of case 11 died of a malignant melanoma of the forearm at the age of 70. Only one aunt was reported as having died of cancer; the maternal aunt of case 13 had breast cancer at the age of 50, but this was an unconfirmed diagnosis. Two uncles died of lung cancer (paternal uncle of case 7 at the age of 70 , and the maternal uncle of case 13, at the age of 56). None of these groups of relatives other than the brothers showed a pronounced excess of malignancies.

Benign neoplastic disease was also confirmed in three patients: case 2, who had a congenital haemangioma, subsequently developed a lipoma on the left lower chest; the mother of case 6 also had a limpoma removed from the left axilla at the age of 28 , and the paternal cousin of case 14 had a fibroadenoma of the breast at the age of 15 years.

Cancers in other family members. Extended pedigrees relating to the child's third and higher degree relatives were available for only five of the 14 cases, although details of one or more lines of inheritance were given in two further families. With the exception of families 3,4 , and 5 , the cancers confirmed in the known relatives were apparently unremarkable in their histological types and ages at onset, the only unusual neoplasm being a hydatidiform mole in a fourth degree relative of case 1 .

The pedigree of case 4 has already been discussed in detail by Pearson et al. ${ }^{11}$ This family shows features of the typical SBLA cancer family syndrome first described by $\mathrm{Li}$ and Fraumeni: soft tissue sarcoma and adrenal cortical tumour in two siblings, and early onset breast cancer in the mother. The mother's paternal grandmother also had breast cancer at the age of 64 and her paternal cousin had a seminoma diagnosed at the age of 23 .

The pedigree of case 3 is shown in the Figure. Although the parents, aunt, uncle, and cousins of this child are all well at the time of writing, there are clear indications that the SBLA cancer family syndrome has been inherited from the father's mother's family. The paternal grandmother de- 


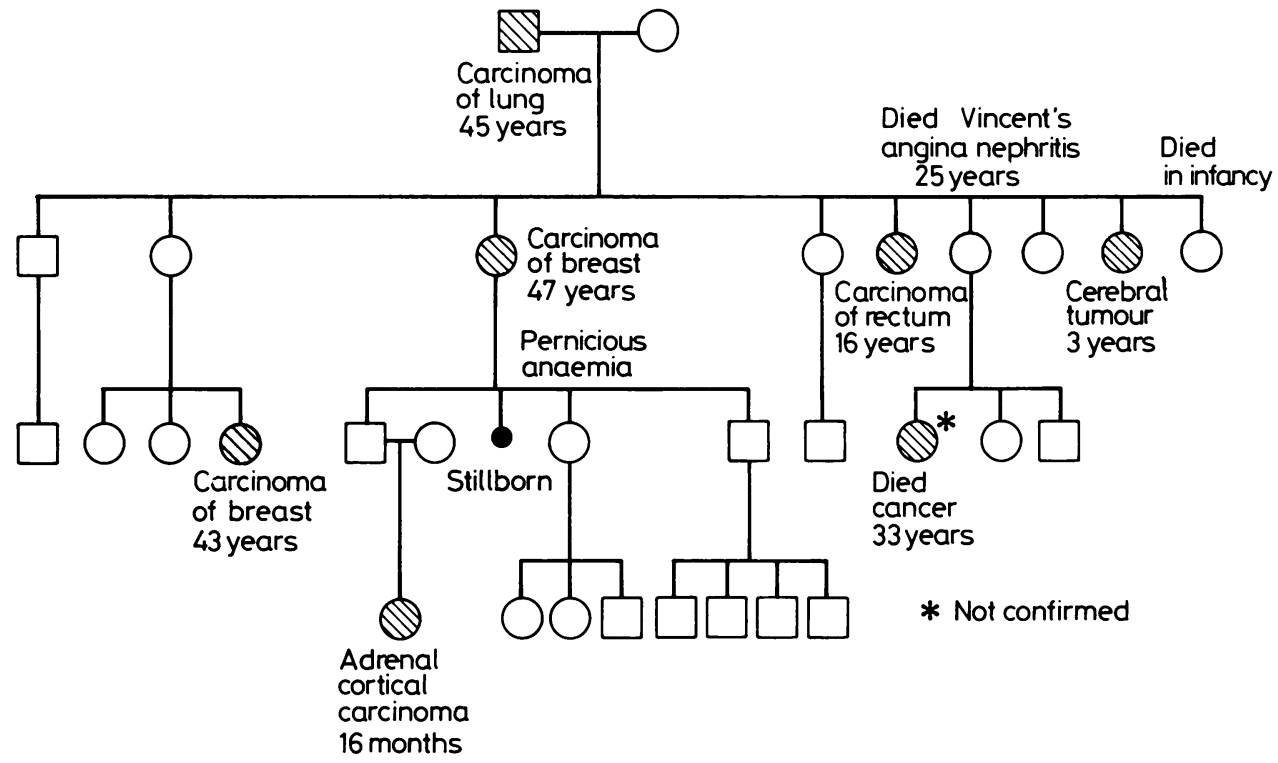

Figure Pedigree of case 3.

veloped carcinoma of the left breast at the age of 47 . Death certificates of two of her sisters showed that one died of cancer of the rectum at the age of 16 , and the other of a cerebral tumour at the age of 3 . The father's cousin was treated for breast cancer at the age of 43 , and another cousin is said to have died of cancer in her 30s. The paternal grandmother's father died of lung cancer at the age of 45 . In family 5 the paternal grandfather died at the age of 35 from a cerebral tumour. Further details of this side of the family are, unfortunately, not available.

Second malignancies. Eight of the children, including all those with adenomas, survived their initial neoplasm for periods ranging from 10 months to 24 years. Case 1, however, whose carcinoma was diagnosed at the early age of 8 months recently developed sarcoma of the left breast, which was induced by radiation, 13 years after surgery and radiotherapy. Another case, described by Stewart ${ }^{17}$ but not included in this series, as she was living outside the North West area at the time of initial diagnosis, had an adrenal cortical carcinoma treated by excision and radiotherapy at the age of 18 months, and developed a chondrosarcoma of the fifth and sixth left ribs and a sclerosing osteogenic sarcoma of the sacrum 10 years after treatment.

\section{Discussion}

The incidence of carcinomas in this series is similar to that previously reported, ${ }^{1}$ and confirms the preponderance of girls noted in other series. ${ }^{18} 19$ Presenting symptoms were also similar to those previously reported, with most of the children showing virilisation. The tumours were almost equally distributed between the right and the left glands. Only two of the children were under the age of one year at diagnosis although some of the other cases were symptomatic up to a year or more before diagnosis.

Case 10 was the only child who had hemihypertrophy and whose tumour seemed, therefore, to be associated with a growth disorder syndrome. This case was one of only two boys in the series, and interestingly, although adrenal cortical tumours are generally more common in girls, the association between hemihypertrophy and adrenal cortical neoplasms seems to be more common among boys. ${ }^{2}$ The mother of this child has anomalies of the renal tract, and three of her grandparents were reported to have died of cancer in old age - two of cancer of the bladder-but these were not confirmed. The child himself developed polycythaemia at the age of 3. This condition has been reported as a rare manifestation of adrenal cortical lesions, ${ }^{20}$ and perhaps this was the first symptom of his tumour.

The presence of corneal opacities in case 2 and her mother and siblings raises the possibility that this family may have neurofibromatosis. Brown patches on the skin were reported in case 6 , and in the mother of case 7 . In none of these families, 
however, is there sufficient evidence to confirm this diagnosis.

The possibility of a brain disorder, similer to that reported by Fraumeni and Miller $^{2}$ in two cases in their series, is raised by the sibling of case 8 who is mentally retarded with alternating convergent squint, ocular hypertelorism, and epicanthic folds. The maternal grandmother of this case was investigated for possible raised intracranial pressure in her 20 s, but no evidence of brain tumour was found.

There were no obvious cases of multiple endocrine neoplasia in the series, although case 13 was described as a cretin; the mother of case 5 suffered from diabetes mellitus; and one father and one sibling were said to have gastric ulcers. In case 6 there is a slight possibility of Gardner's syndrome, with the occurrence of sebaceous cysts in both the mother and maternal grandmother.

Overall cancer risks in close relatives were not above expectation, except for the male siblings. The extended pedigrees, however, show that certain families exhibited features of the SBLA cancer family syndrome, in which susceptibility to cancer seems to be inherited in an autosomal dominant fashion. Family 4 was a clear example of this, and there was similar strong evidence in families 3,5 , and 11.

With the exception of case 10 who had hemihypertrophy, the remaining cases may be sporadic, but because extended pedigrees were not available in most of them, no conclusions can be drawn about any possible pattern of inheritance. Genetic susceptibility of a different kind may be indicated, however, by the presence of cutaneous lesions in certain cases and their relatives-for example, haemangioma, lipoma, and café au lait patches. All these manifestations were reported by Fraumeni and Miller in their series of adrenocortical neoplasms. ${ }^{2}$ One further point of interest is that the paternal uncle of case 7 , who had oat cell carcinoma of the lung, became heavily pigmented before his death, probably because of the melanin stimulating hormone produced by the tumour. Oat cell carcinoma of the lung is also associated with Cushing's syndrome, and this child, who had Cushing's syndrome, and her uncle might have had a genetic defect in common.

In three of the four families who probably had the SBLA cancer family syndrome there was evidence of paternal inheritance of cancer susceptibility, so the occurrence of early onset breast cancer in only one of the mothers may be an underestimate of the risk for the mothers of children with adrenal cortical tumours as a whole, and a reflection of the small sample studied. In family 11 the presence of a brain tumour in the child's father and malignant melan- oma in the maternal grandmother may indicate inheritance of susceptibility from both sides of the family in view of the reported association between adrenal cortical carcinoma and malignant melanoma. ${ }^{5}$

Three of the four cases with SBLA family cancer syndrome were under the median age at diagnosis, but apart from this there seems to be little, apart from a family history of neoplasia, which would indicate cancer risk in these children. The occurrence of a second sarcoma induced by radiation in case 1 , and of two such tumours in the additional case described, indicates that continued surveillance of the surviving cases is desirable, especially if radiotherapy has been part of their initial treatment. Where a pattern of cancer compatible with a cancer family syndrome has been recognised, certain family members who are at present well must also be regarded as being at high risk of developing neoplastic disease characteristic of this syndrome, and they should be offered surveillance and, where appropriate, genetic counselling.

We thank Cora Christmas who traced the parents, the general practitioners who gave us permission to approach them for interview, and the staff of the National Health Service central register, Southport, and the family practitioner committees. We also thank the pathologists who sent us material for review.

The Manchester Children's Tumour Registry is supported by the Cancer Research Campaign.

\section{References}

1 Young JL, Miller RW. Incidence of malignant tumours in US children. J Paediatr 1975;86:254-8.

${ }^{2}$ Fraumeni JF Jr, Miller RW. Adrenocortical neoplasms with hemihypertrophy, brain tumours, and other disorders. J Paediatr 1967;70:129-38.

3 Tank ES, May R. Neoplasms associated with hemihypertrophy, Beckwith-Wiedemann syndrome and aniridia. J Urol 1980; 124:266-8

4 Naylor EW, Gardner EJ. Adrenal adenomas in a patient with Gardner's syndrome. Clin Genet 1981;20:67-73.

5 Dargeon HW. Tumors of childhood. New York: Paul B Hoeber, 1960:391.

6 Andler W, Havers W, Stambolis Ch, Medrano J, Stollman B. Renal cell carcinoma following radiation therapy for an adrenal cortical carcinoma. J Paediatr 1978;93:634-6.

7 Kenny FM, Hashida Y, Askari HA, Sieber WH, Fetterman GH. Virilising tumours of the adrenal cortex. Am J Dis Child 1968;115:445-8.

${ }^{8}$ Shimke RN. Genetics and cancer in man. Edinburgh: Churchill Livingstone, 1978:58.

${ }^{9}$ Lynch HT, Mulcahy GM, Harris RE, Guirgis HA, Lynch JF Genetic and pathologic findings in a kindred with hereditary sarcoma breast cancer, brain tumours, leukaemia, lung. laryngeal and adrenal cortical carcinoma. Cancer 1978;41: 2055-64.

10 Li FP, Fraumeni JF Jr. Soft tissue sarcomas, breast cancer and other neoplasms. A familial syndrome? Ann Intern Med 1969;71:747-52.

" Pearson ADJ, Craft AW, Ratcliffe JM, Birch JM, 
Morris Jones P, Roberts DF. Two families with the Li-Fraumeni cancer family syndrome. $J$ Med Genet 1982;19:362-5.

12 Birch JM, Marsden HB, Swindell R. Incidence of malignant disease in childhood: A 24-year review of the Manchester Children's Tumour Registry data. Br J Cancer 1980;42:215-23.

${ }^{13}$ Leck I, Birch JM, Marsden HB, Steward JK. Methods of classifying and ascertaining children's tumours. $\mathrm{Br} J$ Cancer 1976;34:69-82.

14 Birch JM, Hartley AL, Marsden HB, Harris M, Swindell R. Excess risk of breast cancer in the mothers of children with soft tissue sarcomas. Br J Cancer 1984;49:325-31.

15 Regional Cancer Registry. Cancer in the North West Statistics for 1975-78. North Western Regional Health Authority. Department of Epidemiology and Social Oncology, Christie Hospital and Holt Radium Institute, Manchester.

${ }^{16}$ Rothman KJ, Boice JD Jr. Epidemiologic analysis with a programmable calculator. Boston: Epidemiology Resources 1982.
${ }^{17}$ Stewart DR, Jones PHM, Jolleys A. Carcinoma of the adrenal gland in children. $J$ Paediatr Surg 1974;9:59-67.

18 Zaitoon MM, Mackie GG. Adrenal cortical tumours in children. Urology 1978;12:645-9.

19 Jones GS, Shah KJ, Mann JR. Adreno-cortical carcinoma in infancy and childhood: a radiological report of ten cases. Clin Radiol 1985;36:257-62.

${ }^{20}$ Lipsett MB, Hertz R, Ross GT. Clinical and patho-physiologic aspects of adrenocortical carcinoma. Am J Med 1963;35:374-83.

Correspondence to Dr A L Hartley, Department of Epidemiology and Social Oncology, Christie Hospital and Holt Radium Institute, Manchester M20 9BX, England.

Received 24 February 1987 